Supporting Information

\title{
Direct tray and point efficiency measurements including weeping effects through a convenient add-on for air/water simulators
}

Sara Marchini ${ }^{\mathrm{a}, \mathrm{b}, \mathrm{c}^{*}}$, Vineet Vishwakarma ${ }^{\mathrm{a}, \mathrm{b}}$, Markus Schubert ${ }^{\mathrm{b},{ }^{*}}$, Elisabetta Brunazzic, Uwe Hampel ${ }^{\mathrm{a}, \mathrm{b}}$ ${ }^{a}$ Chair of Imaging Techniques in Energy and Process Engineering, Technische Universität Dresden, 01062 Dresden, Germany

bInstitute of Fluid Dynamics, Helmholtz-Zentrum Dresden-Rossendorf, Bautzner Landstraße 400, 01328 Dresden, Germany

cDepartment of Civil and Industrial Engineering, University of Pisa, Largo Lucio Lazzarino 2, 56126 Pisa, Italy

*Corresponding authors: $\quad$ s.marchini@tu-dresden.de (S. Marchini)

m.schubert@hzdr.de (M. Schubert) 


\section{S1. Analysis of the individual phase resistances}

No reliable correlation is available for predicting the mass transfer coefficients pertaining to sieve trays. However, a rough estimate of the ratio of liquid-side and gas-side resistances can be obtained according to Lockett and Uddin ${ }^{1}$. Assuming that both phases can be modelled according to the penetration theory and that the residence time of each fluid element at the interface is the same at both sides, the ratio between the liquid and gas transport coefficients is given by

$$
\frac{k_{\mathrm{L}}}{k_{\mathrm{G}}}=\left(\frac{D_{\mathrm{IA}, \mathrm{L}}}{D_{\mathrm{IA}, \mathrm{G}}}\right)^{0,5}
$$

where $k_{\mathrm{L}}$ and $k_{\mathrm{G}}$ are the mass transfer coefficients for the liquid and the gas phase, respectively. $D_{\mathrm{IA}, \mathrm{L}}$ and $D_{\mathrm{IA}, \mathrm{G}}$ are the diffusivities of isobutyl acetate in water and air, respectively. As reported in Section 4.1, the equilibrium of the system can be described using Henry's law. Using the two-film theory, the ratio of the liquid phase resistance to the mass transfer with respect to the total resistance is given as

$$
\frac{R_{\mathrm{L}}}{R_{\mathrm{tot}}}=\frac{1}{1+\left(\frac{k_{\mathrm{L}}}{k_{\mathrm{G}} \cdot K^{\mathrm{c}}}\right)},
$$

where $K^{\mathrm{c}}$ is the dimensionless Henry's constant.

At $17^{\circ} \mathrm{C}$, the liquid phase resistance is approximately $70 \%$. This shows that the system is neither fully liquid-phase controlled nor fully gas-phase controlled and thus, unsuitable for measuring the singlephase mass-transfer coefficient only.

\section{S2. Assessment of hydrolysis reaction pertaining to species present in the aqueous solution}

At acid pH values, the following acid-catalyzed hydrolysis reaction for isobutyl acetate occurs: 


$$
\mathrm{C}_{6} \mathrm{H}_{12} \mathrm{O}_{2}+\mathrm{H}_{2} \mathrm{O} \leftrightarrow \mathrm{CH}_{3} \mathrm{COOH}+\mathrm{C}_{4} \mathrm{H}_{10} \mathrm{O}
$$

The formation reaction of isobutyl acetate from isobutanol and acetic acid has an equilibrium constant ${ }^{2}$ $K_{\text {eq }}=4$, thus

$$
\frac{\left[\mathrm{CH}_{3} \mathrm{COOH}\right]\left[\mathrm{C}_{4} \mathrm{H}_{10} \mathrm{O}\right]}{\left[\mathrm{C}_{6} \mathrm{H}_{12} \mathrm{O}_{2}\right]\left[\mathrm{H}_{2} \mathrm{O}\right]}=\frac{1}{K_{\mathrm{eq}}}=0.25 .
$$

Since the reaction happens with an excess of water, the system reaches equilibrium at almost complete conversion of the isobutyl acetate.

The kinetics of the reaction depends on the concentration of $H^{+}$ions acting as the acid catalyst. The $\mathrm{pH}$ value of deionized water decreases immediately if in contact with the atmosphere due to the dissolved carbon dioxide. In this study, $\mathrm{pH}=5$ was measured.

Rayne and Forest ${ }^{3}$ reported the kinetic constant (expressed per mol of catalyst) of the reaction at $\mathrm{pH} 4$ and $25^{\circ} \mathrm{C}$ as

$$
\log _{10} \chi_{\mathrm{A}}=-4.02 \mathrm{~mol}^{-1} \mathrm{~s}^{-1}
$$

Considering a first-order reaction, the isobutyl acetate concentration in the sample follows

$$
c_{\mathrm{IA}}(t)=\left.c_{\mathrm{IA}}\right|_{t=0} \cdot \exp \left(-10^{-p H} \chi_{\mathrm{A}} t\right)
$$

It can be concluded that the change in the isobutyl acetate concentration in the sample as a result of the hydrolysis reaction is below $0.1 \%$, provided that the sample is analyzed within two days after the batch preparation.

It should be noted that the neutral and basic hydrolyses have not been considered, since their effects in acid solutions are negligible. 


\section{S3. Established approaches for point efficiency calculation}

Experimental data from the FRI database were analyzed by Zuiderweg ${ }^{4}$ using the slope and intercept method and the following correlations were derived for the froth regime:

$$
\begin{gathered}
\frac{k_{\mathrm{G}}}{\rho_{\mathrm{G}}^{\prime}}=k_{\mathrm{G}}^{\prime}=\frac{0.13}{\rho_{\mathrm{G}}}-\frac{0.065}{\rho_{\mathrm{G}}^{2}} \\
\frac{k_{\mathrm{L}}}{\rho_{\mathrm{L}}^{\prime}}=k_{\mathrm{L}}^{\prime}=0.024 D_{\mathrm{IA}, \mathrm{L}}^{0,25} \\
a h_{\mathrm{f}}=\frac{43}{A_{\mathrm{f}}^{0,3}}\left(\frac{u_{\mathrm{s}}^{2} \rho_{\mathrm{G}} h_{\mathrm{cl}} F P}{\sigma}\right)^{0,53},
\end{gathered}
$$

where $\rho_{\mathrm{G}}^{\prime}$ and $\rho_{\mathrm{L}}^{\prime}$ are the molar gas and liquid densities, respectively, $D_{\mathrm{IA}, \mathrm{L}}$ is the diffusivity of isobutyl acetate in the liquid phase, $A_{\mathrm{f}}$ is the tray free fractional area, $\sigma$ is the liquid surface tension, $a$ is the contact surface between the gas and liquid phase per unit of froth volume, and $F P$ is the flow parameter defined as $\frac{L_{\mathrm{vol}}}{G_{\mathrm{vol}}} \sqrt{\frac{\rho_{\mathrm{L}}}{\rho_{\mathrm{G}}}}$.

From the two-film theory, the number of the overall gas transfer units is given by

$$
N_{\mathrm{OG}}=\frac{\frac{k_{\mathrm{G}}^{\prime} a h_{\mathrm{f}}}{u_{\mathrm{s}}}}{1+m \frac{k_{\mathrm{G}}^{\prime} \rho_{\mathrm{G}}^{\prime}}{k_{\mathrm{L}}^{\prime} \rho_{\mathrm{L}}^{\prime}}}
$$

whereas the point efficiency can be estimated as

$$
E_{\mathrm{OG}}=1-\exp \left(-N_{\mathrm{OG}}\right)
$$

Based on a separate experimental database concerning stripping and absorption systems, the following correlations for estimating the number of liquid and gas transfer units were developed by Gerster et al. ${ }^{5}$ and are known as the AIChE correlations: 


$$
\begin{gathered}
N_{\mathrm{G}}=\left(0.776+4.57 h_{\mathrm{w}}-0.238 F_{\mathrm{s}}+104.8 \frac{L_{\mathrm{vol}}}{L_{\mathrm{w}}}\right) S c_{\mathrm{G}}^{-0,5}, \\
N_{\mathrm{L}}=1.97 \cdot 10^{4} D_{\mathrm{IA}, \mathrm{L}}^{0.5}\left(0.40 F_{\mathrm{S}}+0.17\right) \tau,
\end{gathered}
$$

where $h_{\mathrm{w}}$ is the height of the outlet weir, $F_{\mathrm{s}}$ is the f-factor, $\tau$ is the liquid residence time (that can be estimated as in Equation S4.8) and $S c_{\mathrm{G}}$ is the gas Schmidt number defined as

$$
S c_{G}=\frac{\mu_{\mathrm{G}}}{\rho_{\mathrm{G}} D_{\mathrm{IA}, \mathrm{G}}}
$$

where $\mu_{\mathrm{G}}$ is the gas viscosity. Considering that, from the two-film theory

$$
\frac{1}{N_{\mathrm{OG}}}=\frac{1}{N_{\mathrm{G}}}+\frac{\lambda}{N_{\mathrm{L}}}
$$

$E_{\mathrm{OG}}$ can be obtained using Equation S3.5.

\section{S4. Tray efficiency models}

The perfectly-mixed model describes the highest possible degree of axial liquid mixing. It assumes that the liquid on the tray as well as the incoming vapour are perfectly mixed, so that

$$
E_{\mathrm{MV}}=E_{\mathrm{OG}} .
$$

In this case, the driving force for mass transfer on the tray is everywhere the lowest; thus, this value represents the lower limit for the tray efficiency value. Anyways, in extreme conditions $E_{\mathrm{MV}}<E_{\mathrm{OG}}$ is a possibility.

The plug flow model ${ }^{6}$ describes the lowest possible degree of axial liquid mixing. It assumes that both liquid and vapour traverse through the tray in plug flow, while the inlet vapour is perfectly mixed. For these conditions, the driving force for mass transfer is everywhere the highest; thus, this value represents the upper physical limit for the tray efficiency value, given by 


$$
E_{\mathrm{MV}}=\frac{\exp \left(\lambda E_{\mathrm{OG}}\right)-1}{\lambda}
$$

The AIChE model ${ }^{7}$ is the most applied model for tray efficiency prediction ${ }^{8}$. It is based on the assumptions of constant point efficiency and linear vapour-liquid equilibrium data, while representing partial liquid mixing axially. Considering the axial liquid mixing as a stochastic phenomenon, the molar mixing flux in the liquid phase can be described by a diffusion-like law according to

$$
J_{\mathrm{L}}=-D_{\epsilon} \rho_{\mathrm{F}}\left(\frac{d c}{d z}\right)
$$

where $D_{\epsilon}$ is the eddy diffusion coefficient that can be estimated as

$$
D_{\epsilon}=3.0 u_{\mathrm{s}} h_{\mathrm{cl}}\left(\frac{\rho_{\mathrm{G}}}{\rho_{\mathrm{L}}}\right)^{0,5}
$$

where $u_{\mathrm{s}}$ is the gas superficial velocity and $\rho_{\mathrm{G}}$ and $\rho_{\mathrm{L}}$ are the gas and liquid densities, respectively.

Performing a material balance between the gas and liquid phases, the following equation can be derived

$$
\frac{E_{\mathrm{MV}}}{E_{\mathrm{OG}}}=\frac{1-\exp [-(\eta+P e)]}{(\eta+P e)\left(1+\frac{\eta+P e}{\eta}\right)}+\frac{\exp (\eta)-1}{\eta\left(1+\frac{\eta}{\eta+P e}\right)}
$$

where

$$
\begin{gathered}
\eta=\frac{P e}{2}\left(\sqrt{1+\left(\frac{4 \lambda E_{\mathrm{OG}}}{P e}\right)}-1\right), \\
P e=\frac{Z^{2}}{D_{\epsilon} \tau}, \\
\tau=\frac{h_{\mathrm{cl}} Z L_{\mathrm{w}}}{L_{\mathrm{vol}}},
\end{gathered}
$$

where $L_{\mathrm{vol}}$ is the volumetric liquid flow rate, $L_{\mathrm{w}}$ is the weir length and $Z$ is the flow path length. 


\section{Nomenclature}

\begin{tabular}{|c|c|c|}
\hline Symbol & Description & Unit \\
\hline$a$ & Interfacial area per unit of froth volume & $\mathrm{m}^{-1}$ \\
\hline$A_{\mathrm{f}}$ & Tray free fractional area (hole area/bubbling area) & \\
\hline$c$ & Liquid concentration & $\mathrm{kmol} \mathrm{m}^{-3}$ \\
\hline$D_{\mathrm{ij}}$ & Diffusivity of component $i$ in the phase $j$ & $\mathrm{~m}^{2} \mathrm{~s}^{-1}$ \\
\hline$D_{\epsilon}$ & Eddy diffusion coefficient & $\mathrm{m} \mathrm{s}^{-1}$ \\
\hline$E_{\mathrm{MV}}$ & Murphree vapour-side tray efficiency & \\
\hline$E_{\mathrm{OG}}$ & Murphree vapour-side point efficiency & \\
\hline$F_{\mathrm{s}}$ & Superficial factor $F_{\mathrm{s}}=\rho_{\mathrm{G}}^{0.5} u_{\mathrm{s}}$ & $\mathrm{kg}^{0.5} \mathrm{~m}^{-0.5} \mathrm{~s}^{-1}$ \\
\hline FP & Flow parameter & \\
\hline$G_{\mathrm{vol}}$ & Volumetric vapour flow rate & $\mathrm{m}^{3} \mathrm{~s}^{-1}$ \\
\hline$J_{\mathrm{L}}$ & Molar backmixing flux in the liquid phase & $\mathrm{kmol} \mathrm{m}^{-2} \mathrm{~s}^{-1}$ \\
\hline$k$ & Mass transfer coefficient & $\mathrm{m} \mathrm{s}^{-1}$ \\
\hline$k^{\prime}$ & Mass transfer coefficient & $\mathrm{kmol} \mathrm{s}^{-1} \mathrm{~m}^{-2}$ \\
\hline$K_{\text {eq }}$ & Reaction equilibrium constant & \\
\hline$K^{\mathrm{c}}$ & Henry constant defined as gas/liquid concentration & \\
\hline$L_{\mathrm{vol}}$ & Volumetric liquid flow rate & $\mathrm{m}^{3} \mathrm{~s}^{-1}$ \\
\hline
\end{tabular}




\begin{tabular}{|c|c|c|}
\hline$L_{\mathrm{w}}$ & Weir length & $\mathrm{m}$ \\
\hline$h_{\mathrm{cl}}$ & Clear liquid hight & $\mathrm{m}$ \\
\hline$h_{\mathrm{f}}$ & Height of the froth & $\mathrm{m}$ \\
\hline$h_{\mathrm{w}}$ & Weir height & $\mathrm{m}$ \\
\hline$m$ & Slope of the linearized vapour-liquid equilibrium data & \\
\hline$N$ & Number of transfer units & \\
\hline$P e$ & Peclet number & \\
\hline$R$ & Resistance to mass transfer & \\
\hline$S c_{\mathrm{G}}$ & Schmidt number & \\
\hline$t$ & Time & S \\
\hline$u_{\mathrm{s}}$ & Vapour superficial velocity referred to $A_{\mathrm{b}}$ & $\mathrm{m} \mathrm{s}^{-1}$ \\
\hline$Z$ & Axial coordinate on the tray & $\mathrm{m}$ \\
\hline$Z$ & Flow path length & $\mathrm{m}$ \\
\hline$\eta$ & Parameter in the AIChE tray efficiency model & \\
\hline$\lambda$ & Stripping factor & \\
\hline$\mu$ & Viscosity & Pa s \\
\hline$\rho^{\prime}$ & Molar density & $\mathrm{kmol} \mathrm{m}^{-3}$ \\
\hline$\rho$ & Density & $\mathrm{kg} \mathrm{m}^{-3}$ \\
\hline$\rho_{\mathrm{F}}$ & Froth density (volume of liquid/volume of froth) & \\
\hline$\sigma$ & Surface tension & $\mathrm{N} \mathrm{m}^{-1}$ \\
\hline
\end{tabular}




\section{Subscripts}

G

L

OG

IA

tot
Gas

Liquid

Overall gas

Isobutyl acetate

Total

\section{References}

1. Lockett, M. J.; Uddin, M. S., Liquid-phase controlled mass transfer in froths on sieve trays. Trans IChemE 1980, 58, 166-174.

2. Izci, A.; Uyar, E.; Izci, E., Determination of adsorption and kinetic parameters for synthesis of isobutyl acetate catalyzed by Amberlite IR-122. Chem. Eng. Commun. 2008, 196 (1-2), 56-67.

3. Rayne, S.; Forest, K., Carboxylic acid ester hydrolysis rate constants for food and beverage aroma compounds. Flavour Fragr. J. 2016, 31 (5), 385-394.

4. Zuiderweg, F. J., Sieve trays: a view on the state of the art. Chem. Eng. Sci. 1982, 37 (10), 14411464.

5. Gerster, J. A.; Hill, A. B.; Hochgraf, N. N.; Robinson, D. G., Tray Efficiencies in Distillation Columns: Final Report from the University of Dalaware. AIChE: New York, NY, 1958.

6. Lewis, W. K., Rectification of binary mixtures. J. Ind. Eng. Chem. 1936, 4 (28), 399-402.

7. AIChE, Bubble-tray design manual prediction of fractionation efficiency. AIChE: New York, NY, 1958. 
8. Vishwakarma, V.; Schubert, M.; Hampel, U., Assessment of separation efficiency modeling and visualization approaches pertaining to flow and mixing patterns on distillation trays. Chem. Eng. Sci. 2018, 185, 182-208. 